\title{
Capsule Commentary on Rinne et al., National Burnout Trends Among Physicians Working in the Department of Veterans Affairs
}

\author{
Akira Kuriyama, MD, MPH \\ Emergency and Critical Care Center , Kurashiki Central Hospital, Okayama, Japan.
}

J Gen Intern Med 35(5): 1624

DOI: $10.1007 / \mathrm{s} 11606-020-05717-1$

(C) Society of General Internal Medicine 2020

$\mathrm{P}$ hysicians empathize with weary patients by profession. However, physicians as humans can also get weary and become "burned out." Physician burnout is associated with an increased risk of patient safety incidents, lower professionalism, and reduced patient satisfaction. It is thus important to know which physician will be likely burned out, as well as when and where.

This longitudinal study by Rinne et al. examined burnout trends of physicians working at 140 Veterans Affairs hospitals between 2013 and 2017. ${ }^{1}$ They found that the proportion of burnout was stable over time, ranging from 34.3 to $39.0 \%$. High burnout sites were more likely to be rural, non-teaching, have lower levels of complexity, and have fewer patients. A national study by Shanafelt et al. suggested that physician burnout was more prevalent (43.9-54.4\%) but decreased from 2014 through $2017 .^{2}$ They also suggested that younger age, female, and working more hours per week were risk factors for burnout. Although findings from these two studies somewhat contradict, they elucidated potential individual- and site-level risk factors of burnout for future studies to consider.

Remarkably, Rinne et al. also suggested that the prevalence of burnout in primary care (PC) physicians was over $50 \%$, the highest among several service areas. A recent systematic review suggested that poor work control and greater time pressure were the most common predictors of burnout in $\mathrm{PC}$ physicians. ${ }^{3}$ A cross-sectional study of smaller PC practices in the USA suggested that practice level autonomy was an important determinant of burnout. ${ }^{4}$ Rinne et al. suggested that the prevalence of burnout in rural and non-teaching PC physicians was higher. It is possible that the slightly different results represent a more nuanced perspective and take into account practice characteristics. Longer hours and low workplace control have consistently been shown to increase burnout. Academic practices may reduce burnout by giving providers a greater diversity of practice focus, rather than solely on "cranking out" patients. Continuing efforts to further elucidate the risk of burnout in PC physicians and to seek interventions to prevent it are needed.

Corresponding Author: Akira Kuriyama, MD, MPH; Emergency and Critical Care Center Kurashiki Central Hospital, Okayama, Japan (e-mail: akira.kuriyama.jpn@gmail.com).

\section{Compliance with Ethical Standards:}

Conflict of Interest: The authors has no conflicts of interest to declare.

\section{REFERENCES}

1. Rinne ST, Mohr DC, Swamy L, Blok AC, Wong ES, Charns MP. National Burnout Trends among Physicians Working in the Department of Veterans Affairs. J Gen Intern Med. (SPI 5582).

2. Shanafelt TD, West CP, Sinsky C, Trockel M, Tutty M, Satele DV, Carlasare LE, Dyrbye LN. Changes in Burnout and Satisfaction With Work-Life Integration in Physicians and the General US Working Population Between 2011 and 2017. Mayo Clin Proc. 2019;94(9):1681-1694.

3. Abraham CM, Zheng $\mathbf{K}$, Poghosyan $\mathbf{L}$. Predictors and Outcomes of Burnout Among Primary Care Providers in the United States: A Systematic Review. Med Care Res Rev. 2019:1077558719888427.

4. Edwards ST, Marino M, Balasubramanian BA, Solberg LI, Valenzuela S, Springer R, Stange KC, Miller WL, Kottke TE, Perry CK, Ono S, Cohen DJ. Burnout Among Physicians, Advanced Practice Clinicians and Staff in Smaller Primary Care Practices. J Gen Intern Med. 2018;33(12):21382146 .

Publisher's Note Springer Nature remains neutral with regard to jurisdictional claims in published maps and institutional affiliations. 